\title{
HUBUNGAN KADAR GULA DARAH PUASA DENGAN JUMLAH LEUKOSIT PADA PASIEN DIABETES MELLITUS DENGAN SEPSIS
}

\author{
${ }^{1}$ Siti Chodijah \\ ${ }^{2}$ Agung Nugroho \\ ${ }^{3}$ Karel Pandelaki

\begin{abstract}
Bagian Ilmu Penyakit Dalam Fakultas Kedokteran Universitas Sam Ratulangi
Email:sitichodijah09036@yahoo.com
\end{abstract}

\begin{abstract}
Abstrak: Diabetes mellitus merupakan suatu kelompok penyakit metabolik dengan karakteristik hiperglikemi yang terjadi karena kelainan sekresi insulin, kerja insulin, atau kedua-duanya. Meningkatnya kepekaan terhadap infeksi pada diabetes mellitus disebabkan oleh berbagai faktor (multifaktorial), baik yang disebabkan oleh hiperglikemia maupun gangguan imunitas. Penelitian ini merupakan penelitian deskriptif analitik dengan desain cross sectional, yang mengambil data pasien secara prospektif di ruang rawat inap bagian penyakit dalam Irina C1 sampai C4, IMC, instalasi gawat darurat medik RSUP Prof.Dr.R.D Kandou Manado pada bulan November sampai desember 2012. Subjek dalam penelitian berjumlah 27 orang. Pengukuran variabel kadar gula darah puasa dan kadar leukosit yang diambil dengan selang waktu 3 hari selama pasien di rawat dari pertama terdiagnosis DM dengan sepsis sampai pasien pulang atau sepsis sudah hilang. Berdasarkan analisis koefisien korelasi Pearson antara GDP dengan jumlah leukosit diperoleh $r=-0,429$ dengan $p=$ 0,013. Simpulan: Terdapat hubungan antara kadar gula darah puasa dengan jumlah leukosit pada pasien DM dengan sepsis dengan bentuk hubungan linear negatif, yang artinya makin tinggi kadar gula darah puasa maka makin rendah kadar leukosit.
\end{abstract}

Kata kunci: GDP, leuksoit, DM dengan sepsis.

\begin{abstract}
Diabetes is one of group metabolic disease with characteristic hyperglycemia that happends because insulin disfungtion. Increasing of sensitivity to inflammation of diabetes mellitus cause by many factors. Both caused by by hyperglycemia and immunity disfunction. This research is study with analytic descriptive with cross sectional design, that taking data with prospective at interna department Irina C1 to C4, IMC, Intensif unit care at RSUP Prof.Dr.R.D Kandou Manado in November to December 2012. Total subject in this research are 27 people. The measurement of fasting blood sugar and total leukocyte that taken with time a gap 3 days as long patient still in unit care from the moment patient diagnosed with DM with sepsis until patient charge go home. Basic on analytic correlation koefisien Pearson between GDP with total leukosit found $r=-0,429$ with $p=$ 0,013 . Conclutions: There is relationship between fasting blood sugar with total leukocyte in patient DM with sepsis with form linear negative means more higher fasting blood sugar, more lower total leukocyte.
\end{abstract}

Keywords: GDP, leukocyte, DM with sepsis.

Diabetes mellitus (DM) adalah sekelompok penyakit metabolik yang ditandai oleh tingginya kadar gula (glukosa) dalam darah yang disebabkan kelainan dalam sekresi insulin, aksi insulin atau keduanya. ${ }^{1}$ Diabetes mellitus merupakan penyakit kronik yang cukup banyak diderita oleh penduduk dunia. Indonesia sendiri menempati urutan keempat dalam daftar negara dengan penderita diabetes terbanyak di bawah India, China dan Amerika. ${ }^{2}$

World Health Organization (WHO) memprediksi adanya peningkatan jumlah pasien diabetes yang cukup besar pada 
tahun-tahun mendatang dengan kenaikan jumlah penyandang DM di Indonesia dari 8,4 juta pada tahun 2000 menjadi sekitar 21,3 juta pada tahun 2030. Senada dengan WHO, International Diabetes Federation (IDF) pada tahun 2009 juga memprediksikan kenaikan jumlah penyandang DM di Indonesia dari 7 juta pada tahun 2009 menjadi 12,0 juta pada tahun 2030. Meskipun terdapat perbedaan angka prevalensi,laporan keduanya menunjukkan adanya peningkatan jumlah penyandang DM sebanyak 2-3 kali lipat pada tahun $2030 .^{3}$

Pusat pengendalian dan pencegahan penyakit (CDC) di Amerika Serikat melaporkan bahwa pada tahun 2005 hampir 21 juta orang di USA 7\% dari populasi memiliki DM dengan sepsis. ${ }^{7} \mathrm{Di}$ negara berkembang dimana tingkat kesadaran kesehatan belum begitu baik, infeksi masih merupakan penyebab utama penderita rawat inap di rumah sakit. Pada satu penelitian di Makassar mengenai sebab rawat inap pada penderita diabetes mellitus, ternyata penyebab infeksi merupakan sebab utama,dimana sekitar $45 \%$ diantaranya dengan kaki diabetes terinfeksi. ${ }^{5}$

Diabetes mellitus sering disertai dengan infeksi dan tidak jarang dengan infeksi berat atau sepsis. ${ }^{6}$ Sepsis yaitu suatu respon inflamasi sistemik terhadap infeksi, dimana patogen atau toksin dilepaskan ke dalam sirkulasi darah sehingga terjadi aktivasi proses inflamasi. ${ }^{4}$ Diabetes mellitus (DM) menginduksi defisiensi imun melalui beberapa mekanisme. Salah satunya yaitu peningkatan kadar gula darah akan mengganggu fungsi fagosit dalam chemotaxis dan imigrasi sel-sel inflamasi yang akan terakumulasi di tempat peradangan. $^{5}$

Karena itu peneliti tertarik untuk meneliti adakah hubungan antara kadar gula darah puasa dengan jumlah leukosit pada pasien DM dengan sepsis. Data mengenai pasien DM dengan sepsis di Manado juga tidak tercantum.

\section{METODOLOGI}

Penelitian ini merupakan penelitian deskriptif analitik. Dengan rancangan cross sectional Penelitian ini dilaksanakan ruang rawat inap bagian Ilmu Penyakit Dalam ruang Irina C1, C2, C3, C4, IMC, instalasi gawat darurat medik RSUP Prof. Dr. R. D. Kandou Manado. Penelitian dilaksanakan selama bulan November 2012 sampai Desember 2012.

Subjek penelitian merupakan pasien yang terdiagnosa DM dengan sepsis. Kriteria inklusi dari pasien DM dengan sepsis yaitu pasien yang ditandai dua atau lebih dari gejala SIRS(systemic inflammatory response syndrome) yaitu suhu $>38^{\circ} \mathrm{C}$, nadi $>90 \mathrm{kali} /$ menit,

Respirasi $>20$ kali/menit, dan leukosit darah $>12.000 / \mu \mathrm{L}$ atau $<4000 / \mu \mathrm{L}$ dengan satu fokus infeksi. Pemeriksaan dilakukan dengan mengambil darah pasien untuk memeriksa kadar gula darah puasa dengan jumlah leukosit dengan selang waktu tiap tiga hari dari pertama pasien dirawat hingga pasien pulang atau sepsis menghilang.

Setelah diperoleh data mengenai kadar gula darah puasa dan jumlah leukosit kemudian dilaksanakan editing, coding, entry dan cleaning data (untuk pengecekan kelengkapan data sehingga data dapat terjamin). Kemudian dilakukan analisis korelasi bivariat Pearson dalam program SPSS versi 20.

\section{HASIL PENELITIAN}

Terdapat 788 pasien yang sedang dirawat di ruang rawat inap bagian Ilmu Penyakit Dalam pada bulan NovemberDesember 2012,pada penelitian ini di dapatkan pasien DM tipe 2 dengan sepsis adalah 27 orang yaitu pria 4 orang (15\%) dan wanita 23 orang (85\%) (Tabel 1).

Pada tabel 2 didapatkan pasien DM tipe 2 dengan sepsis yang kelompok umur bukan lansia ( $<59$ tahun) adalah 20 orang (74\%) dan kelompok umur lansia ( $>60$ tahun) adalah 7 orang (26\%). 
Pada Tabel 3 didapatkan pasien DM tipe 2 dengan sepsis berdasarkan jumlah leukosit rata-rata yang memiliki leukosit normal adalah 7 orang (25,9\%) dan yang memiliki leukosit tinggi (leukositosis) adalah 20 orang $(74,1 \%)$.

Pada tabel 4 didapatkan pasien DM tipe 2 dengan sepsis berdasarkan kadar gula darah puasa rata-rata normal adalah 6 orang $(22,2 \%)$ dan yang memiliki kadar gula darah puasa tinggi (hiperglikemia) adalah 21 orang $(77,8 \%)$.

Pada tabel 5 didapatkan rerata umur pasien adalah 52 tahun, yang termuda berumur 31 tahun dan yang paling tua adalah umur 78 tahun, dengan standar deviasi sebesar 11,43.Minimum rerata leukosit pada pasien dalam penelitian ini adalah 7816,00 , dengan rerata maksimum leukosit sebesar 29200. Rerata nilai leukosit pada pasien adalah sebesar 15448,48, dengan standar deviasi sebesar 5339,74.Rerata gula darah puasa pada pasien DM dengan sepsis di ruang rawat inap RSUP Prof Kandou manado adalah sebesar 155,78.

Pada gambar 1 berdasarkan analisis koefisien korelasi Pearson diperoleh $\mathrm{r}=$ 0,429 dengan $\mathrm{p}=0,013$. Hasil ini menyatakan terdapat hubungan sedang dan signifikan antara GDP rerata dan jumlah leukosit rerata $(p=0,013)$. Pada gambar 1 terlihat bentuk hubungan linear negatif antara GDP rerata dan jumalah leukosit rerata. Ini artinya makin tinggi GDP makin rendah jumlah leukosit

Tabel 1. Distribusi pasien berdasarkan jenis kelamin

\begin{tabular}{lcc}
\hline $\begin{array}{l}\text { Jenis } \\
\text { kelamin }\end{array}$ & $\begin{array}{l}\text { Frekuensi } \\
\text { (orang) }\end{array}$ & Persen (\%) \\
\hline & & 15 \\
Pria & 4 & $85 \%$ \\
Wanita & 23 & 100 \\
Total & 27 & \\
\hline
\end{tabular}

Tabel 2. Distribusi berdasarkan kelompok umur

\begin{tabular}{lcc}
\hline $\begin{array}{l}\text { Kelompok } \\
\text { umur }\end{array}$ & $\begin{array}{l}\text { Frekuensi } \\
\text { (orang) }\end{array}$ & Persen (\%) \\
\hline $\begin{array}{l}\text { Bukan lansia } \\
(<59 \text { tahun) }\end{array}$ & 20 & 74 \\
$\begin{array}{l}\text { Lansia } \quad(>60 \\
\text { tahun) }\end{array}$ & 7 & 26 \\
Total & 27 & 100 \\
\hline
\end{tabular}

Tabel 3. Distribusi pasien DM tipe 2 dengan sepsis berdarkan jumlah leukosit rerata

\begin{tabular}{lcc}
\hline Kadar Leukosit & $\begin{array}{l}\text { Frekuensi } \\
\text { (n=27) }\end{array}$ & Persen(\%) \\
\hline Leukopeni & 0 & 0 \\
Normal & 7 & 25.9 \\
Leukositosis & 20 & 74.1 \\
\hline
\end{tabular}

Tabel 4. Distribusi pasien DM tipe 2 dengan sepsis berdasarkan gula darah puasa rerata

\begin{tabular}{lcc}
\hline $\begin{array}{l}\text { Kadar Gula } \\
\text { darah Puasa }\end{array}$ & $\begin{array}{l}\text { Frekuensi } \\
\text { (n=27) }\end{array}$ & Persen(\%) \\
\hline Hypoglikemi & 0 & 0 \\
Normal & 6 & 22.2 \\
Hyperglikemi & 21 & 77.8 \\
\hline
\end{tabular}

Tabel 5. Karakteristik umum subyek penelitian.

\begin{tabular}{lllll}
\hline & Rerata & $\begin{array}{l}\text { Media } \\
\text { n }\end{array}$ & SD & $\begin{array}{l}\text { Minimum- } \\
\text { maksimum }\end{array}$ \\
\hline Umur & 51,88 & 49,00 & 11,43 & $31,00-78,00$ \\
& & & & \\
Leuko & 15448,48 & 14883, & 5339, & $7816,00-$ \\
& & 00 & 74 & 29200,00 \\
GDP & 155,78 & 157,50 & 43,08 & $\begin{array}{l}69,00- \\
244,00\end{array}$ \\
\hline
\end{tabular}

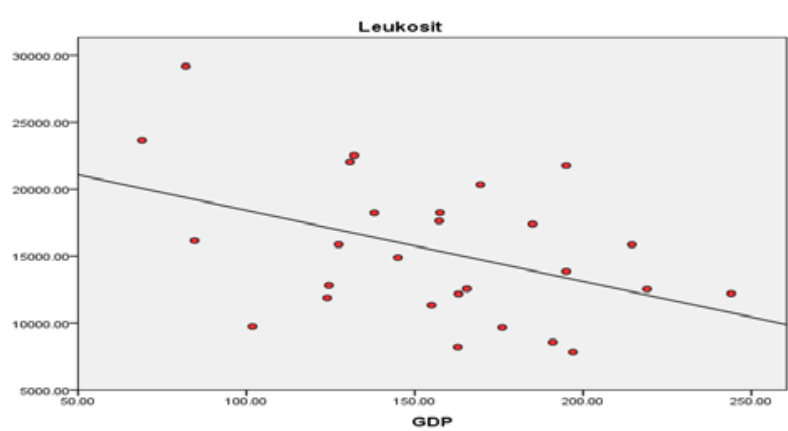

Gambar 1. Scatterplot hubungan GDP dan Leukosit 


\section{PEMBAHASAN}

Dari hasil penelitian deskriptif analitik mengenai hubungan kadar gula darah puasa rerata dengan jumlah leukosit rerata pada pasien DM dengan sepsis di ruang rawat inap RSUP Prof .Dr.R.D Kandou selama bulan November sampai Desember 2012,dari 788 orang yang di rawat ditemukan jumlah pasien DM dengan sepsis sebanyak 27 orang. Dari 27 orang penderita ditemukan yang berjenis kelamin wanita lebih banyak dibandingkan yang berjenis kelamin pria, yaitu 23 orang (85\%) wanita dan 4 orang (15\%) pria. Hasil ini sejalan dengan beberapa penelitian bahwa sebagian besar pasien DM tipe 2 berjenis kelamin wanita. Hasil penelitian Aini Yusra $^{8}$ sebanyak $78,7 \%$ penderita DM tipe 2 adalah wanita. Beberapa faktor resiko seperti obesitas, kurangnya aktifitas fisik atau latihan fisik, usia dan riwayat DM saat hamil, menyebabkan tingginya kejadian DM pada perempuan. $\mathrm{P}$ Hal ini mungkin saja disebabkan karena wanita kurang mendapatkan akses pelayanan kesehatan sehingga pada saat penderita sudah semakin parah sakitnya baru datang ke rumah sakit, sehingga pasien DM yang di rawat di rumah sakit lebih banyak wanita.

Berdasarkan usia, diketahui pasien DM dengan sepsis di ruang rawat inap pada bulan November sampai Desember 2012 paling banyak adalah kelompok umur bukan lansia $<59$ tahun adalah 20 orang (74\%) dan 7 orang (26\%) dengan lansia $>60$ tahun. Hasil ini berbeda dengan penelitian yang dilakukan oleh Barati dkk, ${ }^{5}$ didapatkan kelompok umur lansia terbanyak dengan jumlah 88 orang $(55,7 \%)$. Sejalan dengan modernisasi gaya hidup individu zaman sekarang membuat mereka lebih rentan menderita diabetes mellitus sejak usia muda, contohnya terlalu sering mengkonsumsi makanan cepat saji dan kurangnya berolah raga,maka DM banyak ditemukan pada usia muda.

Pada penelitian ini variabel yang diukur adalah kadar gula darah rerata dengan jumlah leukosit rerata. Kadar gula darah rerata digunakan unutuk melihat keadaan hiperglikemia meningkat pada orang yang menderita diabetes dengan sepsis. Pada penelitian ini didapatkan pasien DM tipe 2 dengan sepsis berdasarkan kadar gula darah puasa rerata normal adalah 6 orang (22,2\%) dan yang memiliki kadar gula darah puasa rerata tinggi (hiperglikemia) adalah 21 orang (77,8\%). Penelitian ini sesuai dengan penelitian Stengenga et al, bahwa pasien DM dengan sepsis mengalami peningkatan kadar gula darah rerata (hiperglikemia). ${ }^{9}$

Pasien DM dengan sepsis sering dihubungkan dengan keadaan berbagai penyakit infeksi. Adanya infeksi menimbulkan respon imun yaitu kenaikan leukosit. Mekanisme respon imun terhadap infeksi pada penderita DM dengan sepsis belum diketahui secara jelas. $^{10}$ Pada penelitian ini didapatkan pasien DM tipe 2 dengan sepsis berdasarkan jumlah leukosit rata-rata yang memiliki leukosit normal adalah 6 orang $(25,9 \%)$ hasil ini mungkin dikarenakan pengaruh dari terapi antibiotic yang digunakan pasien selama dirawat sehingga jumlah leukositnya menurun, pasien dengan leukosit tinggi (leukositosis) adalah 21 orang $(74,1 \%)$.

Hasil penelitian yang dilakukan ruang rawat inap bagian ilmu penyakit dalam RSUP Prof R.D Kandou Manado yang menyatakan bahwa hubungan yang signifikan antara gula darah rerata puasa dengan jumlah leukosit rerata. Bentuk hubungan kedua variabel tersebut yaitu linear negatif yang artinya makin tinggi gula darah puasa rerata maka makin rendah jumlah leukosit rerata. Salah satu faktor yang memungkinkan menjadi penyebab mengapa leukosit menurun adalah karena pengaruh insulin, pasien DM yang menjadi subyek dalam penelitian ini sudah ada yang mendapatkan terapi insulin. Terapi insulin dikatakan memiliki sifat anti inflamasi dan menekan produksi berbagai proinflamasi. ${ }^{11}$ Hal tersebut mendukung bentuk hubungan yang didapatkan dari penelitian bahwa leukosit menurun jika gula darah meningkat. Penyebab lainnya adalah pasien sudah mendapatkan pengobatan antibiotik, sehingga respon pasien berbeda-beda 
mungkin saja pengobatan antibiotik lebih dulu berespon dari pada kerja insulin sehingga leukosit menurun sementara kadar gula darah tetap tinggi.

Kelemahan penelitian ini adalah karena terbatasnya waktu,membuat peneliti tidak mendapatkan pasien dalam jumlah yang banyak. Selain itu terapi obat yang di dapatkan pasien pada penelitian ini tidak di cantumkan oleh peneliti

\section{SIMPULAN}

Berdasarkan hasil penelitian dan pembahasan yang telah di jabarkan maka berdasarkan analisis koefisien korelasi Pearson hasil ini menyatakan terdapat hubungan sedang dan signifikan antara GDP rerata dan jumlah leukosit rerata dengan bentuk hubungan linear negatif antara GDP rerata dan jumalah leukosit rerata. Ini artinya makin tinggi GDP makin rendah jumlah leukosit.

\section{UCAPAN TERIMA KASIH}

Ucapan terima kasih diberikan kepada: dr.Agung Nugroho,SpPD selaku dosen penguji satu yang telah memberikan arahan dan masukan dan kepada Prof.DR.dr. Karel Pandelaki,SpPD-KEMD selaku dosen penguji dua yang telah memberikan masukan yang sangat berguna bagi penulis. Dan kepada semua pihak yang sudah membantu secara langsung maupun tidak langsung yang namanya tidak dapat di sebutkan satu persatu atas ilmu yang berguna bagi penulis.

\section{DAFTAR PUSTAKA}

1. American Diabetes Association. Standards of medical care in diabetes 2012. January 2012[cited 2012 nov 07]. Available from: http://care.diabetesjournals.org/content/35/ Supplement_1/S11.full.pdf+html

2. Alvin P. Diabetes mellitus. In: Fauci, editor. Horrison's principles of internal medicine volume II $\left(17^{\text {th }}\right.$ Edition). United States of America: The McGraw-Hill companies, 2008; p.2275.

3. BP PERKENI. Konsensus pengelolaan dan pencegahan diabetes mellitus tipe 2 di Indonesia. Juni 2011.

4. Baido DR. Diabetes mellitus dan infeksi. Penyakit dalam kedokteran UNHAS. 2011;1:1.

5. Barati M, Taher MT, Golgiri F. Evaluation of diabetes mellitus in patien with sepsis. Clinical of infection disease. 2008;3(4):221-225.

6. Murzalina cut. Procalcitonin pada pasien sepsis yang telah mendapat perawatan di ruang intensif[thesis].[Departemen patologi klinik]:Fakultas kedokteran USU:2007.

7. Esper AM, Moss M, Martin GS. The effect of diabetes mellitus on organ dysfunction with sepsis:an epidemiological study [cited 2009 Feb 13]. Available from: http://ccforum.com/content/13/1/R18.

8. Yusra A. Hubungan antara dukungan keluarga dengan hidup pasien diabetes mellitus tipe 2 [Tesis]. Jakarta: Fakultas Keperawatan UI; 2011.

9. Stengenga ME, Vincent JL, Vail GM, Xie J, Haney DJ, Williams MD, et al. Diabetes does not alter mortality or homeostatic and inflammatory responses in patients with severe sepsis. Crit Care Med 2010;38:539-545.

10. Knapp s. Diabetes and infection . Division of infectious diseases and tropical medicine. Medical university of Vienna 2012;324:1-5.

11. Schuet $\mathbf{P}$, castro $\mathbf{P}$, saphiro $\mathbf{N}$. Diabetes and sepsis:preclinical findings and clinical relevance. Diabetes care:2011;34:771-772. 